\title{
Inhalt.
}

$$
\text { Erstes Kapitel. }
$$

Seite

Einleitnng. Wirtsehaftlieher Begriff der Tantieme; Rlickbliek auf das Hiltere Recht . . . . . . . . . . . . . . . . 1

\section{Zweites $\mathbf{K}$ apitel.}

Voraussetzung für die Anwendbarkeit der in den $§ 8237$ und 245 Abs. 1 enthaltenen Berechnungsvorsehrift.

§ 1. Verhältnis des Vordersatzes zum Nachsatz in jedem der Parsgraphen . . . . . . . . . . . . . . . . . . . . 8

8 2. Bedeutung der Worte „Anteil am Jahresgewinn“ . . . . . . 9

\section{Drittes Kapitel.}

Die Berechnungsvorschrift der $\S 8237$ and 245 Abs. 1.

8 3. Der Begriff des Reingewinns im HGB., insbesondere der „verbleibende Reingewinn" der $\S \$ 237$ and 245 Abs. 1. - Die Abschreibungen . . . . . . . . . . . . . . . . . 23

§ 4. Fortsetzung. Verhältnis der Abschreibungen zu den Räcklagen. - Anhang: Der „jäbrliche Reingewinn“ des § 262 Ziff. 1 . 39

§ 5. Einzelne Rücklagen . . . . . . . . . . . . . . . . . . $\quad .52$

\& 6. Der bei der Aufsichtsratstantieme zu berücksichtigende Vorabzug von mindestens $4 \%$ des eingezahlten Grundkapitals . . . 63

\section{Viertes Kapitel.}

Der reehtliche Inhalt und die Tragweite der $\S \S 237$ und 245 Abs. 1.

§ 7. Unmittelbare und mittelbare Folgerungen aus den $\$ 8237$ und

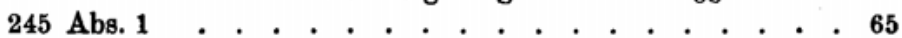

§ 8. Die zwingende Natur der $\$ 8237$ und 245 Abs. 1 . . . . . . 71

$$
\text { Fünftes Kapitel. }
$$

Schlußwort . . . . . . . . . . . . . . . . . . . . . . 83

Literaturverzeichnis . . . . . . . . . . . . . . . . . . . 86 
